\title{
Sobre el texto del Lysis de Decembrio. Revisión y nuevas propuestas
}

\author{
Elena Gallego Moya \\ Universidad de Murcia \\ egallego@um.es
}

Recibido: 20 de junio de 2013

Aceptado: 9 de julio de 2013

\section{RESUMEN}

En este trabajo se analiza el texto de la traducción latina del Lysis de Platón llevada a cabo por Pier Candido Decembrio, teniendo en cuenta las dos únicas ediciones existentes, la editio princeps de Gallego Moya de 2001 y la de Martinelli Tempesta de 2009, así como las observaciones de este autor en un artículo de 2010. Una nueva lectura de los manuscritos que transmiten la traducción latina, así como del manuscrito que contiene el texto griego utilizado por Decembrio, lleva a la autora a ofrecer correcciones y nuevas propuestas al texto latino de las ediciones.

Palabras clave: Traducciones del humanismo. Crítica textual. Pier Candido Decembrio. Platón. Lysis.

Gallego Moya, E., «Sobre el texto del Lysis de Decembrio. Revisión y nuevas propuestas», Cuad. Fil.

Clás. Estud. Lat. 33.2 (2013) 381-400.

\section{Review and New Proposals for the Lysis by Decembrio}

\begin{abstract}
In this paper we analyze the text of the Latin translation by Pier Candido Decembrio of Plato's Lysis, taking into account the only two existing editions, the editio princeps of Gallego Moya (2001), and the edition of Martinelli Tempesta (2009), as well as the remarks found in a new article by Martinelli Tempesta (2010). A new reading of the manuscripts that transmit the Latin translation and of the manuscript that provides the Greek text used by Decembrio leads the author to provide corrections and new readings to the text of both of the editions.
\end{abstract}

Keywords: Translations of humanism. Textual criticism. Pier Candidus Decembrius. Plato. Lysis.

Gallego Moya, E., «Review and New Proposals for the Lysis by Decembrio», Cuad. Fil. Clás. Estud. Lat. 33.2 (2013) 381-400.

SuMARIo 1. Introducción. 2. Las dos ediciones del Lysis de Decembrio: GM y MT. 2.1. Planteamiento ecdótico. 2.2. El texto. 2.3. Algunas observaciones sobre el aparato crítico. 3. Conclusiones. 4. Referencias bibliográficas. 


\section{INTRODUCCIÓN}

Durante más de cinco siglos había permanecido inédita la traducción latina debida a Pier Candido Decembrio del Lysis de Platón ${ }^{1}$. Existían estudios sobre los manuscritos, sobre la naturaleza de la traducción decembriana y sobre algunos otros aspectos $^{2}$, pero no la edición completa de esta traducción latina del diálogo ${ }^{3}$. En el año 2001, en homenaje al profesor R. Düchting ${ }^{4}$, ofrecí la editio princeps del Lysis de Decembrio, que partía de los dos manuscritos que se conocen, el de Ferrara, Biblioteca Comunale Ariostea II 66 (= F) y el de Madrid, UCM BH $129(=\mathrm{M})$; para la edición tuve también en cuenta el manuscrito griego que utilizó nuestro humanista, el Wroclaw, Biblioteka Uniwersytecka Akc. 60/49 (olim Breslau, Gymnasium Fridericianum, cod. I) ${ }^{5}$. La edición del texto iba precedida de una breve introducción que informaba sobre aspectos de la traducción ${ }^{6}$, sobre el texto ${ }^{7}$ y los criterios seguidos en ella ${ }^{8}$; la acompañaban unas notas que constituyen el aparato crítico?

En el año 2009 S. Martinelli Tempesta publicó su edición del Lysis de Decembrio $^{10}$. En 2010 volvió sobre el Lysis en un artículo de $A c m e^{11}$ para dar cuenta de que

${ }^{1}$ También durante mucho tiempo se había considerado perdida; $c f$. Zaccaria (1956, p.54).

${ }^{2}$ Cf. por ejemplo: Hankins (1990) o Martinelli Tempesta (1997).

${ }^{3}$ Se habían dado a la luz algunos fragmentos: cf. Zaccaria (1956, p.54), transcripción del prefacio; y Hankins (1990, II, pp.419-420 y 595-596), edición del prefacio y del comienzo del diálogo.

${ }^{4}$ Cf. Gallego Moya (2001). Allí agradecía al profesor González Rolán que me hubiese dado a conocer dicha traducción y proporcionado copia de los manuscritos.

${ }^{5}$ El manuscrito contiene, entre otros textos, el Lysis de Platón, que ocupa los ff.25r-46v. A la cabeza del manuscrito se lee: Est P. Candidi, emptus Senis 1442 die XIII ${ }^{a}$ Sept. Presenta completo el tratado; las eliminaciones que encontramos en la traducción latina se deben al propio Decembrio. Sobre este manuscrito, véase, por ejemplo, Martinelli Tempesta (1995).

${ }^{6}$ Esta traducción, de la que informaba Decembrio en una carta dirigida a Alfonso de Cartagena, fechada el 1 de julio de 1456 (edición y traducción de esta carta en González Rolán-Moreno-Saquero 2000, pp.406407), estaba dedicada a Ottaviano Ubaldini. Se había realizado sobre un manuscrito griego propiedad de Decembrio ( $c f$. nota anterior). Iba precedida de un prefacio en el que Decembrio explicaba que no había traducido el texto griego en su totalidad; del tratado, decía, había tomado eas dumtaxat partes quae minus abhorrerent a nostris moribus. Estas informaciones del prefacio se veían confirmadas en la traducción, una traducción resumida en la que se omitían pasajes de distinta extensión y contenido: aquellos en los que se aludía de un modo $\mathrm{u}$ otro al amor homosexual (de ellos, los que no podían eliminarse eran sustituidos por referencias al amor heterosexual), así como otros que no consideraba necesarios para el sentido; incluso un pasaje muy extenso en la parte final, probablemente debido al 'cansancio' del traductor. En esta breve introducción destacaba, además, que la traducción de Decembrio es bastante literal, su conocimiento del griego no muy bueno, y su versión latina, poco elegante; $c f$. Gallego Moya (2001, pp.93-94).

${ }^{7}$ Descripción de los manuscritos F y M; relación entre ellos; y razones por las que prefiero F como manuscrito base de mi edición; $c f$. Gallego Moya (2001, pp.94-97).

${ }^{8}$ Cf. Gallego Moya (2001, pp.97-98).

${ }^{9}$ En ellas se ofrecen las variantes o lecturas no elegidas, y otros datos textuales; $c f$. Gallego Moya (2001, pp.112-114). Aparecen al final, no a pie de página, porque nuestra edición formaba parte de un volumen con trabajos variados y no era fácil ofrecer el apparatus criticus como suele ser costumbre.

${ }^{10} C f$. Martinelli Tempesta (2009). La edición va precedida de una amplia Introducción en la que se abordan las siguientes cuestiones: I. Pier Candido Decembrio e il testo del Liside; 2. Il testo greco di riferimento; y 3. Caratteristiche della traduzione. Sigue a la Introducción una Nota al texto, que trata sobre: I. La tradizione manoscritta; 2. I rapporti tra i testimoni; y 3 . Criteri di edizione.

${ }^{11}$ Cf. Martinelli Tempesta (2010). 
conoció mi edición cuando la suya estaba en un avanzado proceso de impresión, por lo que no pudo incorporar nada de ella, y para ofrecer la corrección de algunos errores de su edición, que había advertido tras la lectura de la mía y tras una nueva revisión del texto; también señalaba ciertas discrepancias con el planteamiento ecdótico y con algunas lecturas de mi edición, hecho siempre alentador en el campo científico, y que a mí también me ha llevado a revisar, después de doce años ${ }^{12}$, el trabajo que publiqué en 2001, así como a leer con provecho los suyos, con el fin de corregir lo que fuera necesario, o considerar el motivo de las distintas opciones.

Vuelvo, pues, al texto del Lysis, expresando, en primer lugar, mi satisfacción porque haya sido objeto nuevamente del interés que merecía, y tratando, en definitiva, de contribuir con nuevas observaciones a un mejor conocimiento del mismo.

Me referiré con GM a mi edición de 2001, y con MT a la edición de Martinelli Tempesta de 2009; al artículo de Martinelli Tempesta publicado en Acme en 2010 me referiré con MT 2010.

\section{LAS DOS EDICIONES DEL LYSIS DE DECEMBRIO: GM Y MT}

\subsection{PLANTEAMIENTO ECDÓTICO}

En la transmisión del texto contamos únicamente, al menos hasta el momento, con los dos manuscritos citados, F y M; ambos son independientes entre sí, pues ninguno es copia del otro ${ }^{13}$, pero el texto que presentan, salvo en algunos casos concretos, es muy semejante. En cuanto a la relación cronológica que existe entre F y M, es de cercanía, pues ambos manuscritos se pueden fechar en el tercer cuarto del siglo XV (MT p.113). Otra cuestión más compleja es saber cuál de ellos, a partir de las diferencias de algunas lectiones que presentan uno y otro, es testigo de las lecturas más cercanas al original ${ }^{14}$.

Pese a no existir absoluta certeza, tanto GM como MT consideran que F, que presenta una redacción 'más piadosa', y, por tanto, más coherente con las intenciones expresadas por Decembrio en el prefacio - y con el modo de proceder en el resto de la traducción-, estaría más cerca del original del autor ${ }^{15}$. La redacción de M presentaría 'innovaciones' significativas en algunas lecturas ${ }^{16}$, sobre todo en perpulchri y pulcher, frente a perdocti y doctus de $\mathrm{F}^{17}$, además de otros pequeños cambios.

${ }^{12}$ Volví, no obstante, a este diálogo desde una óptica distinta en un trabajo realizado en colaboración con el profesor Castro de Castro: $c f$. Castro de Castro-Gallego Moya (2010).

13 Así opinan GM y MT; lo muestran los errores separativos entre ambos manuscritos.

${ }^{14}$ Así lo expresa también Martinelli Tempesta (MT 2010, p.266): «La vera difficoltà consiste nello stabilire il rapporto cronologico tra queste modifiche, non essendo possibile affermare, senza margini di dubbio, quali vengano prima e quali dopo»».

${ }^{15}$ La expresión 'more pious' para referirme a F se debe a Hankins (1990, II, p.420). Recuerdo aquí, como ya he mencionado, que Decembrio dejó sin traducir pasajes que se referían de un modo u otro al amor homosexual y 'suavizó' otros que no podía eliminar (además, omitió otras partes que no tenían que ver con estos contenidos).

16 Más adelante serán comentadas.

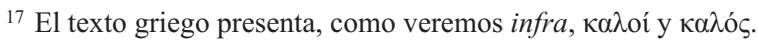


Según GM, tales innovaciones (perpulchri y pulcher de M) pudieron deberse a la intervención de un copista que tuviera acceso al texto griego y que pudo corregir lo que consideró un desajuste en la traducción; pero también plantea la hipótesis de que ambas lectiones (perdocti/ perpulchri y doctus/pulcher) estuvieran ya en el propio original de Decembrio, bien sea presentando en el texto perdocti y doctus y añadiendo en el margen la traducción literal del texto griego, es decir perpulchri y pulcher respectivamente (con la intención de salir al paso de quienes le podían criticar su equivocación); o bien sea traduciendo primero literalmente con las lecturas perpulchri y pulcher, y corrigiéndolas posteriormente con perdocti y doctus ${ }^{18}$.

MT, por su parte, ofrece una propuesta interesante, a saber, que estos cambios (perpulchri y pulcher, así como algunos otros ${ }^{19}$ ) se deben a una revisión del propio P. Candido Decembrio. Pasado un tiempo después de haber realizado su traducción, en la que estarían las lecturas perdocti y doctus, las habría corregido en perpulchri y pulcher, con el propósito de acercar el texto latino a la fuente griega. Del texto originario, destinado a Ottaviano Ubaldini, procedería, por medio de otra copia, el manuscrito $\mathrm{F}^{20}$. Del mismo «esemplare autoriale» o «idiógrafo», después de haber sido sometido a algunos cambios por Decembrio, procedería $\mathrm{M}$. El manuscrito M presentaría, por consiguiente, lectiones posteriores, a saber, una serie de correcciones, puntualizaciones o 'repensamenti' de su autor ${ }^{21}$. Martinelli Tempesta basa su propuesta en que M se copió en el entorno de la casa de Decembrio, y en que en esta copia Angelo Decembrio, hermano de Pier Candido, tuvo algún protagonismo ${ }^{22}$.

${ }^{18}$ Esta hipótesis y alguna otra sugerencia puede verse en GM p.101, n.28.

19 Da cuenta de estos cambios en MT p.147: 33-4 sita est $\mathrm{F}$ : posita est $\mathrm{M} ; 43$ prodocti $\mathrm{F}$ (perdocti corr. Hankins): perpulchri M; 65 doctus F: pulcher M; 161 Iconomicam F: Economicam M; 162 Iconomica F: Economica $\mathrm{M} ; 185$ facile $\mathrm{F}$ et i.m. al(iter) M: maxime i.t. M; 263 felices pueri uel equi cursores amici $\mathrm{F}$ : felicitas est pueri et equi cursoris amici M; 359 ergo $\mathrm{F}$ : uero M; 375 amicicia plena $\mathrm{F}$ : amicicie plena $\mathrm{M} ; 457$ dicimus $\mathrm{F}$ : diximus M. Los números indican las líneas de la edición de MT.

${ }^{20} \mathrm{El}$ manuscrito $\mathrm{F}$, aunque paleográficamente parece más reciente que $\mathrm{M}$, presenta, sin embargo, la redacción más cercana al original; $c f$. MT p.149.

${ }^{21}$ Cf. MT p.146: «Le variazioni ancora percepibili, tuttavia, non sono tali da far pensare a due distinte redazioni: si trata, piuttosto, di correzioni e ripensamenti su singoli dettagli, attuati di norma allo scopo di rendere la traduzione più coerente con il dettato greco».

${ }^{22}$ Cf. MT 2010, pp.266-267: « (...) in un secondo tempo, l'idiografo fu probabilmente rivisto dall'autore - non necessariamente in vista di una ulteriore circolazione-, tenendo conto del testo greco, ed è propio da questo manoscritto rimasto in casa Decembrio che Angelo Decembrio, la cui mano è stata riconosciuta da Vincenzo Fera [2005] sui margini di M (...), fece copiare il testo del Lysis nell'attuale manoscritto di Madrid». Esta mano, sin embargo, como Martinelli Tempesta indica, no se encuentra en los folios del Lysis. Martinelli Tempesta también contempla la hipótesis de que fuera Angelo Decembrio el autor de los cambios, pero le resulta más verosímil que fueran debidos al propio Pier Candido («Si potrebbe pure considerare l’ipotesi di una revisione -realizzatasi sull'antigrafo del Madrileño M -operata da Angelo in polemica con il fratello, ma non ci sono prove che suffraghino una ricostruzione di tale tenore, e inoltre in questo caso perderebbero visibilità le stoccate di Angelo nei confronti di Pier Candido, presenti invece direttamente a margine degli altri due opuscoli in M. Più verosimile mi resulta pensare a una versione, leggermente meno edulcorata e in qualche punto più corretta, che Pier Candido aveva approntato per sé (...) - e sulla quale Angelo era riuscito in qualche modo a mettere la mani»; $c f$. MT p.115). Por último, es posible, según Martinelli Tempesta, que esta copia se hiciera sin el conocimiento de Pier Candido, pues, como ya se ha mencionado, las relaciones entre los hermanos no eran buenas (cf. MT p.149). 
Si esto es así, llama la atención, sin embargo, que en esta revisión de la traducción por parte de Decembrio, destinada en buena parte, como indica Martinelli Tempesta, a acercar el texto latino al original griego, quedaran sin modificar palabras como $\kappa \alpha \lambda \lambda i i^{\omega} v$,

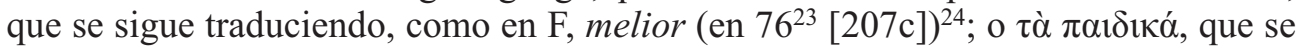
sigue traduciendo, como en F, puellas (en $243[212 \mathrm{~b}]^{25}$ ); o ó $\delta \dot{\varepsilon}$, que se mantiene como illa (en 247 [212c]), igual que en $\mathrm{F}^{26}$. La revisión se habría limitado, pues, en todo caso, a muy pocos lugares (cf. supra n.19); algunos de ellos no tienen que ver con un acercamiento al texto griego; otros no mejoran, en mi opinión, el texto de $\mathrm{F}$.

Pese a estas observaciones, si aceptáramos la hipótesis de que fue el propio Decembrio el responsable de tales cambios, deberíamos plantearnos la siguiente pregunta: ¿Cuál es, en realidad, el texto que ha de darse como la edición de Decembrio, el primero o el corregido, aunque fuese por el propio autor? Sobre todo, teniendo en cuenta que la redacción de F, como explica MT (p.115) estaría destinada a Ottaviano Ubaldini y a ser divulgada, mientras que la de M estaría pensada para uso privado. Pero la pregunta más importante, a mi juicio, es: ¿Cómo podemos estar seguros de que fue Decembrio quien realizó las correcciones?

Partiendo de estos presupuestos, GM y MT han adoptado distintas posturas en sus respectivas ediciones. GM prefiere $\mathrm{F}$ como manuscrito base porque su redacción se considera más cercana al original del autor; MT prefiere M porque, según su planteamiento, presenta cambios introducidos por el propio Decembrio y sería, por así decir, la versión última del Lysis. Esta elección es la responsable fundamental de las diferencias, pocas, que existen entre sus ediciones ${ }^{27}$, aunque, como veremos, también existen en ellas otras lecturas que corregir.

Una última cuestión, igualmente compleja, se refiere a la filiación de los manuscritos. GM propone que F y M proceden de un mismo arquetipo, pues presentan errores comunes como daui ${ }^{28}$ o la lectura moribus ${ }^{29}$-sobre los que trataré más adelante ${ }^{30}$-, pero entre el arquetipo y las copias de $\mathrm{F}$ y M existirían con probabilidad co-

${ }^{23}$ Esta numeración corresponde a la edición de MT, como más adelante se explicará. Aporto también la del texto griego.

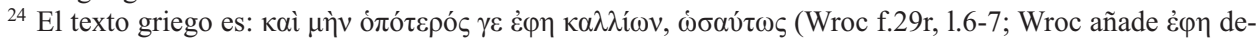
trás de $\gamma \varepsilon$ ) y la traducción: Et quidem uter vicissim sit melior.

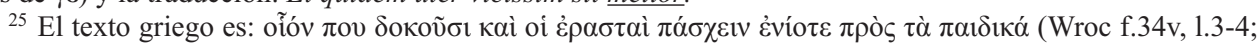

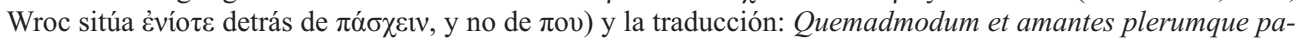
tiuntur erga puellas.

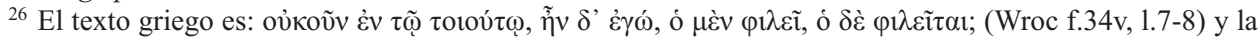
traducción: Num in hoc hic quidem amat, illa uero amatur?

${ }^{27}$ Predominan, en efecto, las coincidencias, porque los manuscritos son muy semejantes, y porque tanto GM como MT, pese a la 'fidelidad' a sus respectivos manuscritos, optan por las lecturas del otro en algunos casos. Basten de muestra algunos ejemplos de coincidencias: 8 sic (lectura de F), 11 satius (lectura de F), 55 illi (lectura de F), 408 re (lectura de F), 431 medico (lectura de F), 375 amicitiae (lectura de M), 426 soli (lectura de $\mathrm{M})$ o 457 diximus (lectura de $\mathrm{M}$ ).

${ }^{28}$ En lugar del correcto claui.

${ }^{29}$ Corregida por Hankins en hominibus, conjetura que sigue GM.

${ }^{30} \mathrm{Tal}$ vez menos significativos, pero también dignos de tener en cuenta son otros errores comunes como: nundum (205 y 477), operitur (156), inconcinitas (279), esedarius (103) у eya (129, 429 y 456). Considero poco probable que fuesen faltas del propio Decembrio. 
pias intermedias; y así, por ejemplo, el modelo de F presentaría incipit y explicit, mientras que el de M los habría omitido ( $c f$. GM, p.96). Distinta es la propuesta de MT, que considera que, por una parte, el hecho de que ambos manuscritos no estén lejos del ambiente del autor $y$, por otra, la presencia de algunas variantes explicables como 'repensamenti' del autor y no como innovaciones de un copista, llevan a pensar en un «idiógrafo móvil»».

Como decía al principio, estas páginas derivan de la relectura de mi edición y de la atenta y útil lectura de los trabajos de Martinelli Tempesta, y están destinadas a mejorar nuestro conocimiento del Lysis de Decembrio, con correcciones y nuevas propuestas. Vamos, por tanto, a comenzar nuestro recorrido dando cuenta de los datos.

\subsection{EL TEXTO}

Si comparamos el texto de las ediciones de GM y MT encontramos las siguientes diferencias ${ }^{32}$ :

1 P. GM (= F): Petri MT; 2 de Vbaldinis GM (= F): de Vbaldini $\mathrm{MT}^{33} ; 7$ admodum sum $\mathrm{GM}(=\mathrm{F})$ : sum admodum $\mathrm{MT}(=\mathrm{M}) ; \mathbf{1 5}$ hominibus $\mathrm{GM}$ (= coni. Hankins): moribus $\mathrm{MT}$ (= F y M); 17 Virgilium GM (= F y M): Vergilium MT; 23 referuntur GM $(=\mathrm{F}$ y $\mathrm{M})$ : referunt $\mathrm{MT} ; \mathbf{3 4}$ sita est $\mathrm{GM}(=\mathrm{F})$ : posita est $\mathrm{MT}(=\mathrm{M}) ; \mathbf{4 3}$ perdocti $\mathrm{GM}$ $\left(=\mathrm{F}^{34}\right)$ : perpulchri $\mathrm{MT}(=\mathrm{M}) ; 48$ inquit ille $\mathrm{GM}(=\mathrm{F})$ : ille inquit $\mathrm{MT}(=\mathrm{M}) ; \mathbf{5 6} \mathrm{Me}$ nexenum $\mathrm{GM}(=\mathrm{F}$ y M): Menexenus $\mathrm{MT} ; 65$ doctus $\mathrm{GM}(=\mathrm{F})$ : pulcher $\mathrm{MT}(=\mathrm{M})$; 72 puer inquam GM (= F y M): inquam puer MT; 105 hoc GM (= F): hec MT (= M); 116 quae adhuc GM (= F): adhuc MT (= M); 129 eia correxi GM: eya $\mathrm{MT}(=\mathrm{F}$ y $\mathrm{M})$; 162 de re oeconomica $\mathrm{GM}\left(=\mathrm{M}^{35}\right)$ : de Economica $\mathrm{MT}(=\mathrm{F})$; 156 opperitur correxi GM: operitur MT (= F y M); 169 filium GM (= F y M): filius MT; 176 existimans $\mathrm{GM}$ (=F y M): exisimans $\mathrm{MT} ; \mathbf{1 8 5}$ facile $\mathrm{GM}\left(=\mathrm{F}\right.$ y $\mathrm{M}^{\text {i.m. }}$ ): maxime $\mathrm{MT}(=\mathrm{M})$; 189 poterunt $\mathrm{GM}(=\mathrm{F})$ : poterint $\mathrm{MT}(=\mathrm{M}) ; 212$ quomodo $\mathrm{GM}$ : quoniam $\mathrm{MT}^{36} ; \mathbf{2 1 2}$ 13: contentiosus est $\mathrm{GM}(=\mathrm{F})$ : est contentiosus $\mathrm{MT}(=\mathrm{M}) ; 233$ sit $\mathrm{GM}$ : fit $\mathrm{MT}(=\mathrm{F}$

\footnotetext{
${ }^{31}$ En cuanto a su planteamiento ecdótico, $c f$. MT pp.145-150. En MT 2010, p.266 explica: «...da un làto il fatto che entrambi i manoscritti non siano lontani dall'ambiente dell'autore, dall'altro la presenza di alcune varianti spiegabili como repensamenti d'autore e non come semplici innovazioni di uno scriba, inducono a concludere che non si può parlare di un archetipo, ma si deve piuttosto pensare a un "idiografo" che a distanza di qualche tempo ha subito qualche lieve modifica (un "idiografo mobile")».

${ }^{32}$ Los números corresponden a la línea en que se encuentran las lectiones según la edición de MT (la edición de GM no presenta numeración de las líneas). Se presenta, primero, la lectura de GM y entre paréntesis el manuscrito o manuscritos que la avalan; a continuación, la de MT seguida igualmente de la pertinente información. Si se trata de una conjetura, se indica. Cuando se comentan las lectiones, al número que indica la línea de MT se añade el número de párrafo correspondiente al texto griego.

${ }^{33}$ Las lecturas de 1 y 2 pertenecen al incipit, que solo ofrece $\mathrm{F}$.

${ }^{34}$ En F se lee prodocti (por perdocti) debido a una resolución incorrecta de la abreviatura de la preposición, como ya vió Hankins (1990, II, p.420). Esta lectura podría estar así en la copia utilizada por F.

${ }^{35}$ Aunque, como bien indica MT 2010, p.268, n. 28, en M parece leerse te en vez de $r e$.

${ }^{36}$ GM y MT resuelven de modo diferente la abreviatura.
} 
y M); 263 felices $<$ quibus $>$ pueri et equi cursores amici $\mathrm{GM}(=\mathrm{F})^{37}$ : felicitas est pueri et equi cursoris amici $\mathrm{MT}(=\mathrm{M}) ; 297$ hoc $\mathrm{GM}(=\mathrm{F})$ : hec $\mathrm{MT}(=\mathrm{M}) ; 298$ conuersus sic $\mathrm{GM}(=\mathrm{F})$ : sic conuersus $\mathrm{MT}(=\mathrm{M}) ; 321$ iniuriam $\mathrm{GM}(=\mathrm{F}$ y $\mathrm{M})$ : iniuria $\mathrm{MT}$; 329 minus alteri $\mathrm{GM}(=\mathrm{F}$ y $\mathrm{M})$ : alteri $\mathrm{MT} ; 337$ quomodo $\mathrm{GM}$ : quoniam $\mathrm{MT}^{38} ; \mathbf{3 5 1}$ non GM (=F): num MT (= M); 359 ergo GM (=F): uero MT (= M); 362 ipsis GM (=F y M): ipsi MT; 371 quomodo GM: quoniam $\mathrm{MT}^{39} ; 416$ malum sit $\mathrm{GM}$ (=F y M): malum MT; 420 quid GM $\mathrm{GM}^{40}$ : quod MT; 429 eia correxi GM: eya MT (= F y M); 436 morbus GM (= F y M): morbum MT; 454 num GM (= M): non MT (=F); 456 eia correxi GM: eya $\mathrm{MT}$ (=F y M); 464 somnio GM (=F y M): somno MT; 477 amicus GM (=F y M): amicum MT; [479s.] Platonis de amicitia liber finit a P. Candido e Graeco traductus in Latinum feliciter GM (= F) $)^{41}$ : om. MT.

Estas diferencias, cuyo número se verá reducido sustancialmente después de corregir una serie de errores, confirman, como ya he mencionado, que los manuscritos son muy semejantes. Veamos las razones de estas diferentes lectiones:

\subsubsection{LA MAYORÍA DE LAS DIFERENCIAS DERIVA DE QUE GM ESCOGE LAS LECTURAS DE F Y MT LAS DE M}

Encontramos trasposiciones en 7, 48, 212-213 y 298; alternancia entre singular y plural del neutro (hoc/ haec) en 105 y 297; otros cambios en 34 (sita est/ posita est), 351 (non/ num), 185 (facile/ maxime), 359 (ergo/ uero); omisiones de un término en MT en 116 (quae) y 162 (re). Otras diferencias de mayor importancia se observan en 43 (perdocti/ perpulchri), 65 (doctus/ pulcher) y 263 (felices <quibus $>$ pueri et equi cursores amici/ felicitas est pueri et equi cursoris amici).

Poco significativas son generalmente las trasposiciones, pues nada dicen de la bondad o no de un manuscrito. Lo mismo puede decirse de la alternancia hoc/ haec, pues, como es sabido, estos neutros se pueden utilizar de modo casi indistinto ${ }^{42}$.

En cuanto a otras diferencias, en 34 [203a] sita est, lectura de F, me parece, como lectio difficilior, preferible a posita est de M, que supone, en mi opinión, una

${ }^{37}$ GM añade quibus; la lectura et es tomada de M (frente a uel de F).

38 Ocurre lo mismo que en 212 y 371.

39 Ocurre lo mismo que en 212 y 337.

${ }^{40} \mathrm{~F}$ presenta la abreviatura $q d$, que GM resuelve como quid.

41 Solo F presenta explicit.

${ }^{4}$ En 105 [208b] GM presenta hoc, lectura de F, y MT presenta hec, lectura que leía en ambos manuscritos; sin embargo, Martinelli Tempesta en 2010, al advertir la diferencia de lectura entre ambos (hoc F/ hec M;

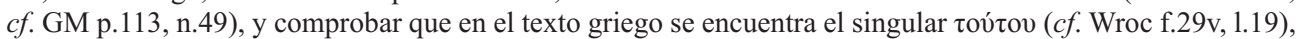
estima más correcta la lectura hoc, de F (cf. MT 2010, p.264, n.6). En 297 [213d] GM escoge hoc (=F) y MT hec $(=\mathrm{M})$; en este caso el texto griego no ayuda, pues no presenta pronombre. En 295 [213d] tanto GM como MT presentan hoc; en 2010 Martinelli Tempesta explica que escogió esta lectura porque así lo leía en ambos manuscritos, pero, al observar ahora -como también en 105-que presentan diferentes lecturas (hoc F/ hec M; cf. GM p.114, n.90), escoge hec, en coherencia con los criterios ecdóticos adoptados, como en 297 (MT 2010 , p.264, n.8). Considero que, respetando también estos criterios, MT 2010 podría mantener hec en 105, pese al

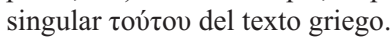


glosa explicativa de $s i t a^{43}$. MT considera posita una modificación del autor; de ser así, este cambio es, ciertamente, de calidad inferior al de la primera lectio.

En 351 [215a] considero preferible non, lectura de F, que se lee en GM, frente a num, de M, porque, aunque el contexto puede requerir, como indica Martinelli Tempesta (MT 2010, p.264, n.9), una partícula interrogativa ${ }^{44}$, esta no es estrictamente necesaria en latín ${ }^{45}$, y, por otra parte, el original griego presenta un adverbio de negación ov̉ $\chi^{46}$, que habría llevado a Decembrio a escribir non, manteniendo la negación. Por el mismo motivo, debería mantenerse, en mi opinión, en 454 [218b] la lectura non, de F, que ofrece MT, en vez de num que se lee en M y elige GM, pues el texto griego presenta $0 \hat{v}^{47}$.

En $185[210 b]^{48}$, la lectura facile, que ofrece $\mathrm{F}$, frente a maxime de $\mathrm{M}$, tiene a su favor, en mi opinión, que la vemos también corregida en $\mathrm{M}^{i . m}$, en donde se lee facile. El texto griego no aporta información, puesto que no hay ningún adverbio con el que se corresponda ${ }^{49}$. MT (p.149) explica que no existe certeza sobre qué lectura es la más antigua, pero se inclina también por la antigüedad de facile; sin embargo, prefiere $m a$ xime, que sería, en su opinión, un 'repensamento' (o 'second thought') del autor.

En el caso de ergo de GM (=F) frente a uero de MT (= M), de 359 [215b], el texto griego tampoco aporta información que pueda ser útil en la elección de uno u

${ }^{43}$ El texto griego no aporta información, pues en él no hay forma verbal que corresponda a sita/ posita est.

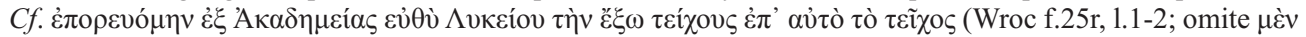
detrás de $\dot{\pi} \pi \circ \rho \varepsilon v o ́ \mu \eta v$; escribe $\varepsilon \dot{\pi}$ ' en lugar de $v \pi$ '). Por otra parte, la traducción no se corresponde exactamente

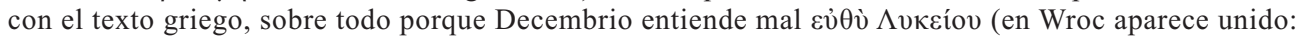

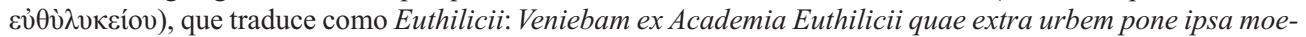
nia sita/ posita est.

${ }^{44}$ Otra cuestión es si num sería la partícula adecuada en este contexto y otros similares.

${ }^{45}$ En efecto, como es sabido, aunque las interrogativas directas en latín van introducidas en la mayoría de los casos por partículas interrogativas (además de otros elementos), también se encuentran sin partícula, como originariamente; $c f$. Kühner-Stegmann (1992, p.501).

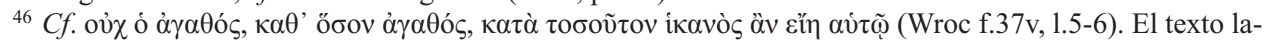
tino es: Non/ num igitur bonus in quantum bonus in tantum sibi ipsi erit sufficiens?

${ }^{47} C f$. ஸे oủ $\mu \varepsilon ́ \mu \nu \eta \sigma \theta \varepsilon$ vข̃v; (Wroc f.41r, 1.8; Wroc añade vṽv), que es traducido: Non/ num recordaris? En esta ocasión, curiosamente, GM y MT ofrecen, respectivamente, la lectura del manuscrito no elegido. Otro lugar que apoya esta lectio es 412 [216d], donde el adverbio de negación oủ es traducido, tanto en F como en M, por non, y así lo mantienen GM y MT. El texto latino es: Tu non existimas?, traducción del griego ov̀ $\delta$ 'oủK oľci; (Wroc f.39r, 1.11). Sin embargo, hay que reconocer que, en otro pasaje (310 [214b]), el texto griego presenta un adverbio de negación ov̉к, y F y M coinciden en ofrecer num. El texto latino es num huius-

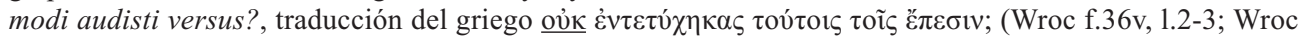
omite ì delante de oủк). Por último, num también aparece en F y M como traducción, por ejemplo, de la par-

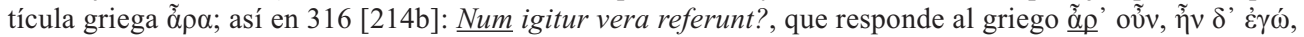
$\varepsilon \tilde{乛} \lambda \varepsilon_{\gamma}{ }_{0 v \sigma \mathrm{v}}$; (Wroc f.36v, 1.8-9). En definitiva, como indicaba supra, la traducción de las partículas griegas plantea problemas y el latín de Decembrio no es muy correcto. Por tanto, cuando existen divergencias en los manuscritos, no se puede estar del todo seguro de si Decembrio utilizó non o num. En la mayoría de estos casos, por otra parte, nonne parece la partícula oportuna, pues hace prever una respuesta afirmativa, frente a num, generalmente negativa. Sin embargo, como ya he recordado, non es correcto (seguido evidentemente de interrogación).

${ }^{48}$ El texto es: Sic-inquam-res habet, amice Lysis: in quibus enim docti esse uidebimur, omnes se nobis facile/ maxime concedent, non graeci modo et barbari, verum mulieres atque viri (...).

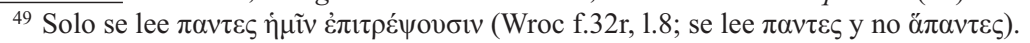


otro término ${ }^{50}$. Dos líneas antes (en 357) aparece uero; en 359, la repetición de uero podría servir para confirmar la idea; en cuanto a ergo, representaría una conclusión de lo que se dice. La duda permanece en cuanto a la lectura genuina; no obstante, tanto GM como MT coinciden en que la lectura originaria pudo ser ergo de F; la lectura uero, de M, sería, según MT, producto de una 'remeditazione' que tendría como finalidad aportar coherencia al razonamiento (MT p.148 y MT 2010, p.268). Sin embargo, creo poco posible que Decembrio se detuviera a pensar sobre las partículas de este texto, sobre todo cuando deja sin revisar otros lugares mucho más significativos. En definitiva, la elección previa de manuscrito ( $\mathrm{F}$ o M) es la responsable de la elección de una u otra partícula por parte de GM y MT para traducir $\delta \dot{\varepsilon}^{51}$.

En 116 [208c], por lo que respecta a la omisión de quae en $\mathrm{M}$, que mantiene Martinelli, la considero, en efecto, una omisión por parte del copista ${ }^{52}$; en el texto griego $^{53}$ aparece $\tau$ ó $\delta \varepsilon$, complemento directo de $\varepsilon i \pi \varepsilon ́$; Decembrio traduciría, sin duda, et quae adhuc mihi dicito.

Otra omisión se da en 162 [209d] ${ }^{54}$ : de re oeconomica $\mathrm{GM}\left(=\mathrm{M}^{55}\right)$ : de Economi$c a \mathrm{MT}(=\mathrm{F})^{56}$. El manuscrito $\mathrm{F}$ omite $r$ e detrás de $d e$; en el manuscrito M parece leerse de te, como advierte $\mathrm{MT}^{57}$, lectura que, evidentemente, no se entiende en este tex-

${ }^{50}$ El contexto es este: Qui uero non diliget, nec amicus erit ulli. Fateor. Qui uero/ ergo non amat, nec ami-

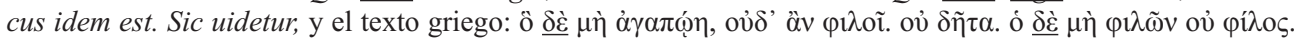

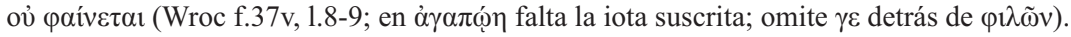

${ }^{51} \delta \dot{\varepsilon}$, por otra parte, aparece en muchas ocasiones en este pasaje, que va de 346 [215a] (Qui autem non se ament, quomodo amici?) a 366-367 [215c] (Amici ergo nequaquam erunt, non multi se inuicem putantes. Vere). En él se da la siguiente sucesión de partículas: 346 autem $(=\delta \dot{\varepsilon}) \ldots 348$ uerum $(=\dot{\alpha} \lambda \lambda \lambda \dot{\alpha} \delta \dot{\eta}) \ldots 351$ igitur $(=\tau i ́$ $\delta \dot{\varepsilon}) \ldots 353$ autem $(=\delta \dot{\varepsilon} \gamma \varepsilon) \ldots 355$ autem $(=\delta \grave{\varepsilon}) \ldots 357$ vero $(=\delta \dot{\varepsilon}) \ldots 359$ ergo/ uero $(=\delta \dot{\varepsilon}) \ldots 361$ igitur $(=$ oưv $) \ldots$ 366 ergo $(=\delta \varepsilon \dot{\gamma} \gamma)$. La partícula $\delta \varepsilon \dot{e}$ es traducida por Decembrio como autem en 346, 353 y 355; como uero en 357; como ergo en 366; y como ergo o uero en 359. Martinelli Tempesta (MT p.148 y MT 2010, p.268) explica que la partícula conclusiva ergo (366) conviene al final del pasaje, y en 359 prefiere la lectura uero, en vez de ergo. La propuesta tiene justificación, pero es igualmente posible que la lectura ergo de 359 constituya una primera conclusión, y ergo de 366 , la segunda.

${ }^{52}$ MT 2010, p.268, n.27 piensa, por el contrario, que quae es un error de F, reproducido en GM.

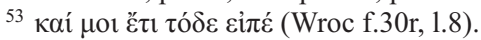

${ }^{54}$ El contexto es: Vtrumne putet ipsius oeconomicam se curae tuae subicere debere, cum te exsistimarit me-

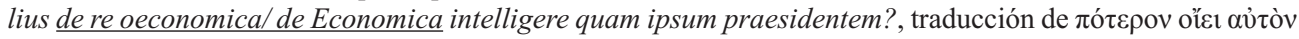

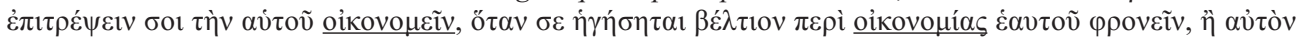

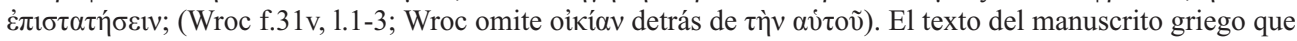

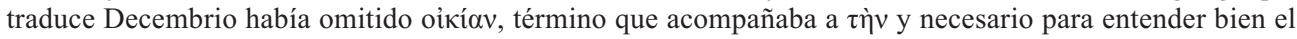

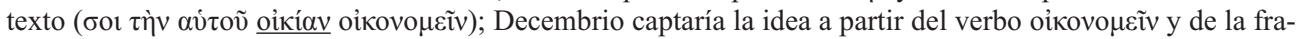
se siguiente, y tradujo el texto, en el primer caso, como mejor pudo (oeconomicam subicere).

55 Sobre si M presenta re o te, véase infra.

${ }^{56}$ En los manuscritos los términos oeconomicam y oeconomica aparecen escritos de modo distinto, divergencia que GM no advierte en su aparato crítico, como indica MT 2010, p.268 (véase también MT pp.147-148).

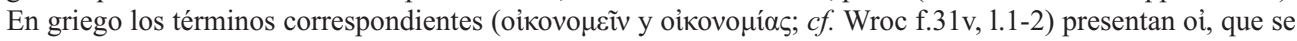
corresponde con el diptongo latino oe. El manuscrito F (f.20v, 1.1-2) lo indica con una I longa especial, muy distinta a cualquier otra $i$ mayúscula del manuscrito (la que más se asemeja es la de Illa de f.22r, 1.16). El manuscrito M (f.98v, 1.9-10) representa el diptongo con una especie de $e$ mayúscula (se asemeja a $€$ ) distinta a todas las que encontramos, por ejemplo, Ego en f.98v, 1.14 o Eya en f.104r, 1.22.

${ }^{57}$ Así dice en el aparato crítico: 162 de F: de te M (an variam auctoris lectionem, scil. de re, male intellectam scriba vergaverit adfirmare nequeo); cf. MT p.160. 
to y que podría ser una equivocación derivada de que el escriba de $\mathrm{M}$ entendiera mal re y escribiera te. Por otra parte, la opción de Martinelli Tempesta (MT 2010, p.268, n.28) de considerar que se trata, como en 161 (oeconomicam), del adjetivo sustantivado, y que re debe eliminarse, también me parece posible. No obstante, esta sustantivación, en este contexto y con el valor de 'administración de la casa o hacienda', parece rara $^{58}$. Creo que no se puede dar una solución definitiva y varias hipótesis son dignas de tener en cuenta: 1) que el texto latino presentara la alternancia (oeconomicam $^{59}$ (subicere), de re oeconomica ${ }^{60}$ ), manteniendo, de alguna manera, la uariatio

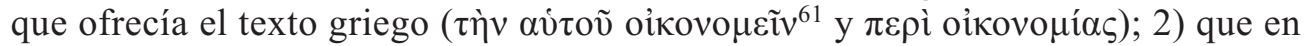
ambos casos se sustantivara el adjetivo (oeconomicam y de oeconomica); y 3 ) que en ambos casos estuviera el término res (rem oeconomicam y de re oeconomica).

Finalmente, las diferencias verdaderamente significativas son las que afectan a perdocti GM/ perpulchri MT en 43 [203b], y doctus GM/ pulcher MT en 65 [207a], sobre todo por estar en la base de la diferente elección de manuscrito por parte de GM y MT (de F y M respectivamente), y de la diferente valoración de la tradición manuscrita. Como hemos indicado supra, si tenemos en cuenta lo expresado por Decembrio en el prefacio y su modus operandi en la traducción, parece preferible escoger las lecturas perdocti y doctus para traducir $\kappa \alpha \lambda$ oí у $\kappa \alpha \lambda$ ó $\varsigma$, como lecturas originarias. Perpulchri y pulcher serían innovaciones posteriores, ya sea por parte de un copista, o, según Martinelli Tempesta, del propio Decembrio.

Otro lugar importante en cuanto a las diferencias entre F y M y las ediciones de GM y MT es 263 [212e]: felices < quibus> pueri et equi cursores amici GM: felicitas est pueri et equi cursoris amici MT. El texto griego al que corresponde la traduc-

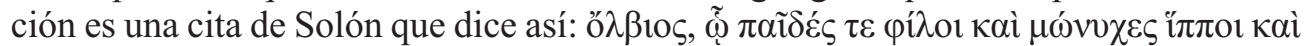

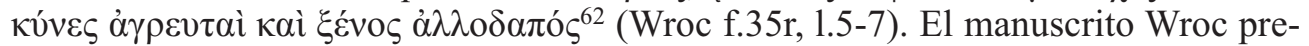
senta la forma de dativo $\tilde{\omega} \sin$ 'iota' ${ }^{63}$, omisión que probablemente advertiría Decembrio. La traducción del texto griego sería: «feliz el que posee ("para el que hay") hijos queridos, caballos, etc.»; se trata, como es evidente, de una oración nominal pura, en la que se sobreentiende el verbo eỉí.

La traducción latina se transmite distinta en los manuscritos y en ambos plantea problemas. En F se lee felices pueri uel equi cursores amici/ uenantesque canes exoticusque comes. En M, felicitas est pueri et equi cursoris amici/ uenantesque canes exoticusque comes. Las diferencias afectan, pues, a la primera parte y, en concreto, a felices/felicitas est, uel/ et y cursores/ cursoris.

\footnotetext{
${ }^{58}$ En el título de la obra de Cicerón Oeconomicus, el adjetivo se ha sustantivado, aunque los ejemplos son diferentes.

59 Entendido como 'la cosa económica', 'los asuntos económicos' o 'la administración de la casa'.

${ }^{60}$ A mi juicio, es posible que el copista que, como propone Martinelli Tempesta, hubo entre el texto originario y $\mathrm{F}$ omitiese, por despiste, el re (o te) que leemos en $\mathrm{M}$; la repetición de estos dos monosílabos, ambos acabados en $e$ (de y re/ te) facilitaría la omisión de uno de ellos.

${ }^{61}$ En este primer caso, se añade, además, en la traducción la dificultad de que Wroc omite el sustantivo

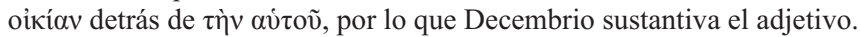

${ }^{62}$ Fr. 13 Diehl y Adrados. La traducción que ofrece Adrados es: «Feliz el que posee hijos queridos, caballos de pezuña sin hendir, perros de caza y un huésped en tierra extraña»; $c f$. Rodríguez Adrados (1956, p.195).

${ }^{63}$ La omisión de iota suscrita es habitual en el manuscrito griego.
} 
En el manuscrito $\mathrm{F}$, el singular ö $\lambda \beta$ ıь esta razón, GM añade un quibus, equivalente al cui que exigiría felix. El sentido del texto griego se mantiene bastante semejante en la traducción latina ${ }^{64}$, porque lo que se dice es que son «felices aquellos que tienen ("para los que hay") hijos, caballos, etc.»; con la inclusión de quibus el problema puede 'resolverse' (pues es evidente que algo falta en el texto) ${ }^{65}$, al menos en lo que se refiere a la sintaxis y al sentido del texto. En cuanto a la métrica, la opción de $\mathrm{F}$ es correcta, salvo en el quinto dáctilo (pues cursores presenta una $e$ larga donde se precisa breve); incluso la palabra uel pudo estar motivada por razones métricas (para evitar la omisión de la $i$ de pueri delante de et, o un hiato). Con la adición de quibus de GM, la métrica se complica bastante.

En cuanto a M, el texto presenta, en mi opinión, mayores problemas, que afectan no sólo a la métrica, sino también a la sintaxis y al sentido. Si se lee felicitas est pueri et equi cursoris amici, el texto no se entiende ni es correcto sintácticamente. La traducción «la felicidad es los hijos, los caballos, etc., como amigos» entendido como «La felicidad consiste en tener por amigos hijos, caballos, etc.» ${ }^{66}$, no es muy verosímil; para entenderlo y traducirlo así faltan elementos sintácticos. Habría que sobreentender, en todo caso, un dativo quibus ( «la felicidad es/ existe para aquellos que tienen ("para los que hay") hijos, caballos, etc.»). Martinelli Tempesta (MT pp.147 y MT 2010, pp.267-268) considera que el texto de M supone una reflexión ('repensamento') de Decembrio respecto a F, con la finalidad de restablecer el sentido, desatendiendo la métrica; pero, según mi criterio, esto no es así.

El tex to de $\mathrm{F}$ me parece, sin duda, más adecuado que el de $\mathrm{M}$, pues, además de estar más cerca del original (como ya se ha recordado), presenta muchos menos problemas; la adición de quibus por parte de GM choca, en efecto, con la pretendida fidelidad a la métrica del dístico que Decembrio pudo desear, pero me parece preferible a la problemática lectura de $\mathrm{M}$.

Hasta aquí me he referido a lo editado por GM y MT. Ofrezco ahora, después de releer los textos, una nueva propuesta, que, según creo, podría ser la solución. Es muy posible que Decembrio escribiera felix $\mathrm{cui}^{67}$, y que a partir de una lectura equivocada de estas dos palabras surgiera felices, que se lee en F. También es posible que escribiera $u e l^{68}$ para facilitar la métrica ${ }^{69}$, o tal vez para justificar amici referido no solo a pueri $^{70}$, sino también a equi, canes y comes.

${ }^{64}$ Otra cuestión es el cambio de lugar de amici en el texto latino, con respecto a pí $\lambda$ or en el texto griego.

${ }^{65}$ Sin duda, un dativo.

${ }^{66}$ Como traduce Martinelli Tempesta; $c f$. MT 2010, p.268.

${ }^{67}$ Por otra parte, he comprobado que otros traductores latinos de este diálogo también ofrecen en este lugar felix cui. Por ejemplo, M. Ficinus (1546, f.124): Felix cui dulces pueri, cui copia equorum/ et cui turba canum sit, tum cui sit nouus hospes, o Io. Serranus (1577, f.212, D): felix cui dulces nati, cui copia equorum,/ cuique canum et sancti cui fauor hospitii.

${ }^{68}$ Lectura que sigo ahora, por fidelidad a F, en lugar del et (de M) que escogí en GM.

${ }^{69}$ Con pueri et, si no se hace hiato, se produciría una elisión.

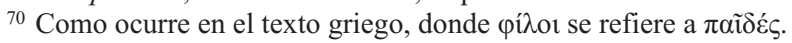


En cuanto a cursores de F como traducción de $\mu \omega ́ v v \chi \varepsilon \varsigma$, plantea problemas. El término $\mu \omega ́ v v \chi \varepsilon \varsigma$ significa 'de pezuñas no partidas', 'de sólidas pezuñas', 'solípedos', indicando la pezuña a modo de casco que tienen los equinos; por tanto, el texto griego habla, en nominativo plural, de 'caballos cascudos', calificando a los caballos con este adjetivo -casi un epíteto-, adecuado a ellos. Decembrio no lo traduce literalmente; tal vez conocía su significado, pero no se adecuaba al texto que quería traducir ${ }^{71}, \mathrm{y}$ por eso debió de pensar en otro término que conviniese a 'caballos', eligiendo el sustantivo cursores, que pudo utilizar aquí como adjetivo ('caballos corredores', 'caballos de carrera'). Esa es la lectura de F, cursores, y, casi sin duda, la primera. En M encontramos cursoris, cuya $i$ breve sí convenía a la métrica ${ }^{72}$-aunque no tanto al sentido-, y que, como sustantivo que es, podía ser complemento del nombre de equi; se puede entender, pues, como 'caballos del corredor', o 'del mensajero', es decir, 'del que lleva los correos', algo así como 'caballos de posta', pero este sentido es poco verosímil.

Mi propuesta es, por $\operatorname{tanto}^{73}$ : felix cui pueri uel equi cursores amici/venantesque canes exoticusque comes.

\subsubsection{ACEPTACión O NO DE UNA CONJetura: 15 hominibus GM (= CONI. Hankins): MORIBUS MT $(=\mathrm{F} \text { Y M })^{74}$}

En este lugar GM acepta hominibus, conjetura de Hankins, y considera que la lectura moribus es un error común de F y M. Martinelli Tempesta mantiene moribus, lectura de ambos manuscritos y afirma que hominibus es una 'conjetura no necesaria', argumentando a favor de moribus que en el ámbito de las pretensiones estilísticas de un prefacio no parece inaceptable el uso traslaticio de boni mores en lugar de boni homines (MT 2010, p.265, n.18). Moribus podría ser, en principio, aceptable, pero el empleo metafórico de mores por homines en un escritor como Decembrio plantea bastantes dudas ${ }^{75}$. A mi juicio, entre hominibus y moribus es preferible hominibus, aunque los problemas siguen existiendo.

En esta nueva lectura del texto, llegué a pensar que Decembrio pudo escribir $a b$ hominibus y que un error de lectura habría dado lugar a a bonis moribus. Sin embargo, el contexto parece precisar la presencia de un adjetivo como bonis, puesto que Decembrio está refiriéndose a 'hombres buenos'. Ahora estoy prácticamente segura de que Decembrio escribió mortalibus $^{76}$ (a bonis mortalibus) ${ }^{77}$, y no moribus (a bonis moribus).

${ }^{71}$ Tanto M. Ficinus como Io. Serranus traducen $\mu \omega ́ v 0 \chi \varepsilon \varsigma$ ï $\pi \pi \mathrm{ol}$ por copia equorum.

${ }^{72}$ Pues así se resuelve el quinto dáctilo.

${ }^{73}$ Pese a que la $e$ de cursores es larga.

${ }^{74} \mathrm{El}$ texto, que pertenece al prefacio, es el siguiente: Verum enimuero ii maxime admirantur-aut potius despiciunt-quae a nobis conscribuntur, qui expertes litterarum nihil nisi quod ipsis placeat colendum putant a bonis moribus/ hominibus.

${ }^{75} \mathrm{Se}$ echa en falta, además, la mención de lugares paralelos que avalen esta propuesta.

${ }^{76}$ Mortalis con el significado de homo está atestiguado en latín desde antiguo (por ejemplo, en Lucrecio), y sobre todo en plural (por ejemplo, en Cicerón), acompañado, generalmente, de multi, omnes o cuncti; en Agustín, Contra adversarium legis et Prophetarum, I, c. VI encontramos el sintagma boni mortales. Será bastante frecuente en el latín de los humanistas.

${ }^{77}$ Agradezco al profesor González Rolán su inestimable ayuda en la solución de este problema. 
Esta nueva propuesta puede constituir la solución al problema. Sin duda, Decembrio escribió a bonis mortalibus, aunque no podemos saber si escribió mortalibus en abreviatura ${ }^{78} \mathrm{o}$ añadiendo sobre la palabra -incompleta- las letras que faltaran ${ }^{79}$. Así estaría, sin duda, en el arquetipo. Las copias no advirtieron la abreviatura y escribieron moribus, lectura que encontramos en F y M y que constituye, como ya decía en GM, un error común.

\subsubsection{OTRAS DIFERENCIAS ENTRE GM Y MT DERIVAN DE DESLICES, ERRATAS, OMISIONES, LECTURAS EQUIVOCADAS DE LOS MANUSCRITOS, ETC.}

Deslices o erratas pueden considerarse las de 17, 72, 129 (429 y 456), 156, 176, 189, 233, 464; omisiones vemos en 329, 416 y [479s.]; resolución de inicial de nombre propio en 1; lecturas equivocadas encontramos en 2, 23, 56, 169, 321, 362, 436, 477; casos especiales son los de 212 (337 y 371), 420 y $454^{80}$. Comentaremos estas divergencias entre las ediciones, que no derivan en este caso de la elección de uno u otro manuscrito.

En el caso de Virgilium y Vergilium de $\mathbf{1 7 ^ { 8 1 }}$, aunque ambas lectiones son posibles, F y M ofrecen Virgilium, y así está en GM; MT edita Vergilium ${ }^{82}$; lo corrige en 2010, aceptando Virgilium. En el caso de $\mathbf{7 2}$ [207c] puer inquam GM (= F y M): inquam puer MT, no se trata en realidad de una variante; el manuscrito M coincide con F; en ambos se lee puer inquam; MT por desliz hace una mera trasposición. Deslices encontramos también en MT en 129 [208d] (429 [217a] y 456 [218b]) donde edita eya en lugar de eia de GM; o en 156 [209c] donde MT presenta operitur en lugar del deponente opperitur, que se lee en GM. Una errata encontramos en MT en exisimans 176 [210a] (por existimans). En 189 [210c] GM $(=\mathrm{F})$ ofrecía poterunt y MT (= M) poterint; MT 2010 acepta poterunt de F. Error o errata es 233 [212b] sit de GM, frente a la lectura correcta fit de MT (= F y M), e igualmente lo es 464 [218c] somno de MT frente al correcto somnio de GM (= F y M) $)^{83}$.

Algunas omisiones en MT son: 329 [214d] minus alteri GM (= F y M): alteri MT, corregido en MT 2010. Por otra parte, MT, que reproduce el incipit, ofrecido solo por F, omite el explicit [479s.], que igualmente ofrece solo F y que dice así: Platonis de amicitia liber finit a P. Candido e Graeco traductus in Latinum feliciter. En GM (como en F) están ambos, incipit y explicit.

\footnotetext{
${ }^{78}$ Para esta abreviatura (en la que sobre moribus -ya sea sobre $o$ o sobre $r$ - encontraríamos una línea ondulada horizontal que equivaldría a tal) véase, por ejemplo, Capelli (1985, p.224).

${ }^{79}$ Podría ser: moribus con las letras tal sobrepuestas en la parte superior, en letra pequeña, a la mitad de la palabra (algo así como mor ${ }^{\text {talibus}) . ~}$

${ }^{80}$ Incluyo 454 en este lugar -y no en el apartado 1- porque GM escoge num, lectura de M, y MT escoge non, de F. Para estas lecturas, véase supra la explicación de 351.

${ }^{81}$ En el prefacio.

${ }^{82}$ Así leía también Hankins.

${ }^{83}$ En F (f.26v, 1.5) se lee somnio y en M (f.104v, 1.6) sonio con un trazo horizontal sobre la primera o, que se resuelve en este caso en $m$, y, por tanto, somnio también.
} 
Otra omisión es la de $\mathbf{4 1 6}$ [216d] malum sit GM (= F y M): malum MT. En este pasaje ${ }^{84}$, tanto $\mathrm{F}$ como $\mathrm{M}$ ofrecen, a mi juicio, malum sit, lectura de GM (frente a la omisión de sit en MT). Si lo observamos en el contexto, en F se lee neque malum sit ne tibi? En M se lee claramente: neque malum sit sicne tibi?

En mi opinión, el copista de $\mathrm{F}$ habría cometido una falta motivada por la repetición de dos palabras muy semejantes (sit y sic), omitiendo una de ellas ${ }^{85}$ (sic según $\left.\mathrm{GM}^{86}\right)$; no obstante, es aquí difícil distinguir con claridad entre $t^{87}$ y $c$, por lo que podemos también aceptar que, como dice Martinelli Tempesta (MT 2010, p.269), en F se lea sic; en este caso, evidentemente, la palabra omitida sería sit.

El manuscrito $\mathrm{M}$ aporta luz al problema. El copista también cometió una falta muy común, la de pasarse de una línea a otra en el texto que copiaba. Por un salto de línea, omite el fragmento que va desde 'Quemadmodum' hasta 'malum sit', que es el que luego añade en el margen. Es muy fácil que se dé un salto de línea en este pasaje. Si miramos el texto latino, hay dos frases casi idénticas: neque bonum neque malum est, y un poco más adelante, neque bonum neque malum sit. Al estar escribiendo la primera frase, el copista habría pasado del primer malum al segundo, escribiendo malum sit, y omitiendo una parte del texto. Después de haber seguido copiando el texto, advirtió el salto de línea; rectificó sit sobreescribiendo est (todavía puede leerse sit debajo de la corrección) y añadió en el margen el texto que se había 'saltado' (Quemadmodum... malum sit). Este sit pertenece, por consiguiente, al texto de Decembrio ${ }^{88}$ (se escribe primero en el texto; luego se rectifica en est y vuelve a escribirse sit en el margen), y en esta ocasión no me parece aceptable la propuesta de Martinelli Tempesta (MT 2010, p.269), según la cual sit sería un añadido banal de M, y en F lo que habría que leer es $\operatorname{sic}^{89}$.

A las diferencias mencionadas hay que añadir la resolución en MT de la abreviatura $P$. de F en Petri (1), frente a GM que la mantiene.

Más significativas son otras diferencias que proceden de una lectura equivocada de los manuscritos y que afectan a la sintaxis del texto; así: 2 Vbaldinis GM (=F): Vbaldini MT, donde la lectura Vbaldini no es posible, porque se trata de un ablativo plural (de Vbaldinis). En el caso de 56 [206d] Menexenum GM (= F y M): Menexenus $\mathrm{MT}^{90}$ y 169 [209e] filium $\mathrm{GM}$ (= F y M): filius MT, las lecturas correctas son las

\footnotetext{
${ }^{84}$ El texto latino dice así: Sic aio diuinans quodammodo boni ac honesti amicum esse quod neque bonum neque malum est. Quemadmodum autem id uaticiner dum loquar audito. Videtur quippe mihi tria quaedam genera ea esse, quod bonum est scilicet et quod malum et quod neque bonum neque malum sit. Sicne tibi? En

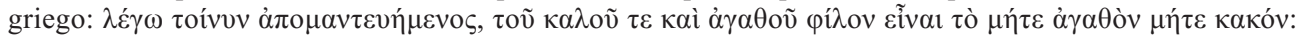

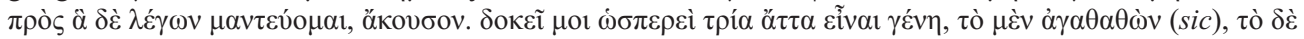

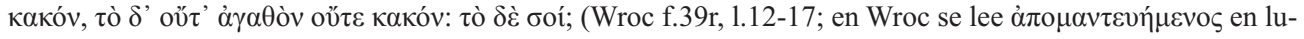

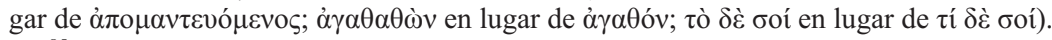

${ }^{85}$ Se trataría de una omisión semejante a la de re en de re oeconomica.

${ }^{86}$ Así lo expreso en el aparato crítico: sicne M: ne F; $c f$. GM p.114, n.118.

${ }^{87}$ Otro ejemplo donde se lee una t final semejante es putet (f.20r, 1.23).

${ }^{88}$ Otra cuestión es que, como ocurre en otros casos, responda o no a un buen latín.

${ }^{89}$ En este caso, como ya he indicado supra, lo que en F, o ya en su modelo, se habría omitido, según mi opinión, sería sit, pero no significaría la ausencia de sit en el texto de Decembrio.

${ }^{90}$ Menexenus también leía, por error, Hankins; MT 2010 lo corrige.
} 
de GM (=F y M), puesto que el texto exige un acusativo. Igualmente deben corregirse las lecturas de MT 436 [217b] morbum $^{91}$ frente a morbus de GM (= F y M) $)^{92}, 477$ [223b] amicum frente a amicus de GM (= F y M $)^{93}, 321$ [214c] iniuria, frente a iniuriam de GM (=F y M), 362 [215b] ipsi frente a ipsis ${ }^{94}$ de GM (= F y M), y 23 referunt ${ }^{95}$ frente a referuntur de GM (= F y M).

Mención especial merece la divergencia, en algunos lugares, de quomodo GM: quoniam MT. Martinelli Tempesta (2010, p.268) señala el error de lectura quomodo de GM en 337 [214e] ${ }^{96}$ y 371 [215c $]^{97}$; a estos dos lugares hay que añadir otro, en 212 $[211 b]^{98}$, que no menciona Martinelli. La abreviatura que ofrecen los dos manuscritos ( $q m$ con un trazo sobre $m$ ) parece indicar que se trata de quoniam (aunque, como explicaré más adelante, esta abreviatura también acepta la resolución quomodo). Sin embargo, la lectura quoniam plantea problemas porque en estos lugares el texto y el contexto parecen rechazar esta conjunción, cuyo valor en latín es causal ${ }^{99}$, motivo principal por el que en un principio descarté esta lectura. En griego aparece en los tres casos un ö $\tau$ completivo; en latín esperaríamos también una completiva de infinitivo porque los verbos de los que en cada caso depende la subordinada se construyen con oración de infinitivo. Pero, ciertamente, el latín de Decembrio no se ajusta a las 'normas del latín clásico', por lo que no es extraño que utilizase, en vez de completiva de infinitivo, una completiva introducida por una conjunción. Sin embargo, frente a las conjunciones esperadas ( ut o quod) encontramos quoniam, que para Decembrio tiene aquí, no un valor causal ${ }^{100}$, sino completivo ${ }^{101}$. La lectio que debe mantenerse en el texto es, por tanto, quoniam ${ }^{102}$, aunque es evidente que el valor completivo no solo

${ }^{91}$ Tal vez el error se deba a que un poco antes de morbus aparece el sintagma propter morbum (F f.26r, 1.2 y M en la misma línea, f.104r, 1.3).

${ }^{92}$ Así se lee en F (f.26r, 1.2-3) y M (f.104r, 1.3).

${ }_{93} \mathrm{El}$ contexto es: (...) nondum enim, quid amicus sit, potentes fuimus inuenire. Tanto en F (f.26v, 1.21) como en M (f.104v, 1.23) encontramos amicus.

94 También en este caso MT 2010 lo corrige.

95 También referunt leían, por error, Zaccaria y Hankins. MT 2010 lo corrige.

96 337: Habemus igitur quinam amici hi sint; sermo quippe nobis innuere uidetur quomodo/ quoniam hi erunt qui boni sunt.

97 371: Iam enim te dicente audiueram et imprimis reminiscor quomodo/ quoniam simile simili et bonis boni aduersi inter se maxime sunt.

${ }^{98}$ El texto es: Scis enim quomodo/ quoniam contentiosus est.

99 También tuvo originariamente un valor temporal, que se limita casi por completo a Plauto. $C f$. KühnerStegmann (1992, II, p.366, n.4).

${ }^{100}$ En el texto del Lysis hay otros ő $\tau$ que son causales, y quoniam los traduce correctamente.

${ }^{101}$ Este valor completivo de quoniam (como el de quia, mucho más frecuente, o el de quomodo, más raro) no es clásico; pertenece al sermo uulgaris; aparece dependiendo de verbos como credere, paret, scire, dicere, etc.; el verbo de la completiva suele estar en indicativo. Está atestiguado, por ejemplo, en la Peregrinatio Egeriae, en varios ejemplos (por ej., 8. 1 paret sane quoniam et ingens fuit; 12.7 dixit nobis quoniam iam aliquot anni essent (con subj.); 12. 2 nullus hominum scit quoniam certum est; 17. 2 credat (...) quoniam nullus Christianorum est; $c f$. Löfstedt (1962, pp.117ss.) y Väänänen (1987, p.73). La difusión de este giro se relaciona con las traducciones latinas de la Biblia; la analogía $\lambda \dot{\varepsilon} \gamma \omega \delta$ เótı $=\lambda \varepsilon \dot{\gamma} \gamma \omega$ ö $\tau \iota$ apoyaría el uso completivo de quoniam; cf. Ernout-Thomas (1964, p.299).

102 Pienso, con muchas dudas, en otra posible hipótesis: que en el original hubiese un quod, cuya abreviatura, no claramente expresada, hubiese podido dar lugar a otra que estaría en la base de quoniam. 
no es clásico sino que es, además, muy raro. En cuanto a la lectura quomodo, que preferí en un primer momento, la abreviatura también acepta esta resolución y quomodo puede introducir, igualmente, una oración completiva; sin embargo, después de revisar los manuscritos, creo preferible aquí quoniam, porque F y M para expresar quomodo utilizan otra abreviatura ${ }^{103}$.

En cuanto a 420 [216e] $q[u i] d \mathrm{GM}^{104} /$ quod $\mathrm{MT}^{105}$, en $\mathrm{F}$ se lee $q d$, que, con dudas, resolví en quid; en $\mathrm{M}^{106}$ se lee quod. Sintácticamente sería más adecuado el interrogativo quid con subjuntivo; hay, además, al final del Lysis un ejemplo muy simi$\operatorname{lar}\left(477-8\right.$ [223b]), donde la lectura es quid (como también admite MT) ${ }^{107}$. Como afirma Martinelli Tempesta (2010, p.268), la abreviación en este lugar de F es ambigua; sin embargo, una nueva revisión del manuscrito me confirma que qd es aquí, en 420, abreviatura de quod $^{108}$, coincidiendo con la lectura que edita Martinelli Tempesta.

\subsection{ALGUNAS OBSERVACIONES SOBRE EL APARATO CRÍTICO}

En este recorrido por el texto del Lysis de Decembrio, nos detenemos ahora brevemente en el aparato crítico. Ambas ediciones, GM y MT, presentan un aparato crítico positivo. GM lo hace en forma de notas al final del texto ${ }^{109}$, tratando de ofrecer toda la información que presentan los manuscritos ${ }^{110}$. MT presenta un aparato crítico a pie de página (con las variantes significativas) y dos apéndices: Apéndice A) divergencias ortográficas y deslices banales y Apéndice B) errores enmendados por el copista.

Las diferencias más importantes entre el aparato crítico de GM y MT derivan, como era de esperar, de la elección de F (por parte de GM) o M (por parte de MT); en el aparato estarán las lecturas del manuscrito no elegido en cada caso, aunque en no pocas ocasiones GM y MT coinciden en elegir la lectura del mismo manuscrito, sobre todo $\mathrm{F}$ en lo que respecta a variantes significativas ${ }^{111}$. En efecto, son considerables los casos en los que F presenta gramaticalmente la lectura correcta frente a M, por lo que

\footnotetext{
${ }^{103}$ La abreviatura quo con un trazo sobre $o$, y, en algunos casos, quomo con un trazo sobre $o$.

${ }^{104}$ Estoy de acuerdo con la sugerencia de Martinelli Tempesta (2010, p.268, n.29) de utilizar en el aparato crítico en este caso () en lugar de [ ] para evitar confusiones.

${ }^{105}$ El contexto es el siguiente: Linquitur autem super haec quid/ quod amicum sit (...). En griego se lee:

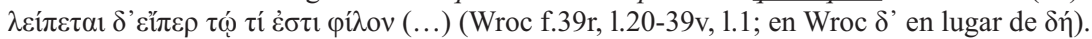

${ }^{106} \mathrm{M}$ f.103v, 1.15 .

${ }^{107}$ En 477-8 se lee: ... nondum enim, quid amicus sit... potentes fuimus inuenire. En F (f.26v, 1.21) se lee nuevamente $q d \mathrm{y}$ en $\mathrm{M}(\mathrm{f} .104 \mathrm{v}, 1.23)$ quid.

${ }_{108}$ El manuscrito F hace de modo distinto la abreviatura qd cuando se trata de quod y cuando se trata de quid (en este último caso un trazo horizontal corta el trazo vertical de la $q$ ).

109132 notas; $c f$. GM pp.112-114.

110 Presento también las variantes en Zaccaria (1956), en el prefacio; y Hankins (1990), en el prefacio y comienzo del diálogo, pero sólo cuando difieren del texto propuesto (cf. GM p.98).

111 Por ejemplo en: 8 sic GM, MT (=F): si M; 11 satius GM, MT (= F): satis M; 58 ego GM, MT (= F): ergo M; 353 nullius GM, MT (=F): nullus M; 408 re GM, MT (=F): res M; 431 medico GM, MT $(=\mathrm{F})$ : amico M, etc. En algunos casos GM y MT escogen M, frente a la lectura incorrecta de F. Por ejemplo, en 375 amicitiae GM, MT (= M): amicicia F; 426 soli $\mathrm{GM}, \mathrm{MT}$ (= M): sibi F o 457 diximus $\mathrm{GM}, \mathrm{MT}(=\mathrm{M})$ : dicimus F. Junto a estas variantes, encontramos otras, menos significativas, que se deben a errores de lectura o erratas.
} 
insisto en afirmar, recordando lo que decía en 2001, que el manuscrito F, además de ser más cercano al original del autor, presenta lecturas más correctas; probablemente contaba con un modelo mejor que el de M, y el copista entendía mejor el texto.

2.3.1. En su artículo de 2010 Martinelli Tempesta (MT 2010, pp.264-265), a la vista de la edición de GM y de una nueva revisión de los manuscritos, añadió en el aparato crítico de su edición y en sus correspondientes apéndices (A y B) un número importante de lectiones o variantes que no había contemplado en su edición de 2009.

En dos de estos lugares conviene hacer una observación. En 368 [215c] se leía en GM prolabamur F: prolabiamur M (GM p.114, n.106); MT 2010 al incorporar esta lectura piensa que en $\mathrm{M}$ se escribió en un primer momento prolabimur y casi de inmediatio (inter scribendum) se corrigió en prolabamur. Ciertamente, el manuscrito deja lugar a dudas porque una vez rehecha la $a$, permanece claramente el trazo de la $i$.

Por otra parte, en 377 [215d] GM había señalado la diferencia de lectura entre F (silicet) y M (scilicet) (GM p.114, n.109). MT 2010 al incorporarla lee silicet en Fa.c. y scilicet en $\mathrm{F}^{\text {p.c. }}$; una nueva revisión del manuscrito (F f.24v, 1.15) me lleva a mantener la lectura silicet en F, pues no es fácil ver el trazo de una $c$. Se trata, no obstante, de un lugar poco claro ${ }^{112}$.

Del mismo modo, Martinelli Tempesta (MT 2010, p.268, n.28) advirtió algunos lugares que debían corregirse en $\mathrm{GM}^{113}$. GM (p.113, n.68) en el aparato crítico de $\mathbf{1 8 5}$ [210b] omite que M presenta la lectura facile en el margen; GM (p.113, n.80) en 233 [212a] lee equivocadamente pater en $\mathrm{F}$, en lugar del correcto uter. En 179 [210a] es posible que en F se lea iniicere, como señala Martinelli, y no inicere, como presenta GM (p.113, n.67) en el aparato crítico, pero no está clara la lectura (cf. F f.20v, 1.17). Algo similar ocurre en 78 [207c]; GM (p.113, n.39) presentaba la siguiente información: omnino M: omino F. Tras una nueva revisión del manuscrito F (f.18v, 1.19) estoy de acuerdo con Martinelli Tempesta en que parece leerse onimo (no creo posible onnno) ${ }^{114}$ (y que lo mismo puede decirse en 147 [209b]; $c f$. F f.20r, 1.9). Probablemente quiso escribir omnio ${ }^{115}$, como abreviatura de omnino, como sí hace en 295 (cf. F f.23r, 1.13).

Por último, con relación a $\mathbf{1 0 7}$ [208b] GM leía daui en ambos manuscritos, considerándolo un error común. En opinión de Martinelli Tempesta (MT 2010, p.266) se trata de una lectura equivocada, pues tanto en $\mathrm{F}$ como en $\mathrm{M}$ se lee claui. Una nueva lectura de los manuscritos me lleva a confirmar lo que ya pensaba en 2001. En el

\footnotetext{
112 Es probable que el copista de F escribiera primero slicet, añadiendo después una especie de $i$, cuyo trazo resulta más grueso que el resto de las letras, pero en el que, como he mencionado, es difícil encontrar el trazo de una $c$. De este modo, silicet sería, en todo caso, la lectura corregida.

113 En 392 [216b] MT 2010 (p.265) añade en el apéndice A la siguiente información (omitida en MT): amicicie M: amicitie F, e indica que esta divergencia ortográfica no es señalada por GM. En efecto, tal y como expongo en los criterios de mi edición de 2001 (GM p.98), la grafía ha sido normalizada; en estos ejemplos he regularizado $t$ (MT regulariza $c$ ). Por esta razón, por ejemplo, edito inimicitia cuando en los dos manuscritos se lee inimicicia (cf. F f.25r, 1.10: inimicicia amicitie; y M f.103r, 1.15: inimicicia amicicie). Por tanto, no aparecen en el aparato crítico de GM variantes ortográficas del tipo ti/ci (amicitia/ amicicia), e/ae (amicitie/ amicitiae), etc.

114 Ciertamente, también podría leerse omino u omnio. Es difícil la lectura de esta palabra.

115 Con un trazo recto horizontal en la parte superior.
} 
manuscrito M (f.97v, 1.2) se lee, sin ninguna duda, daui; la $d$ de daui es la misma que la de, por ejemplo, concedet en el mismo folio ( $\mathrm{M} \mathrm{f.97v,} \mathrm{1.4)} \mathrm{o} \mathrm{darii}(\mathrm{M} \mathrm{f.99v,} \mathrm{1.26);}$ en cambio, en palabras como praeclari (M f.95r, 1.9), clarissime (M 95v, 1.9) o clam (M f.99v, 1.5) se observa claramente la separación de las dos consonantes ( $c$ y $l$ ), y de ningún modo podrían confundirse con una $d$. En cuanto al manuscrito $\mathrm{F}$ (f.19r, 1.18) también se lee daui; como en el caso de M, las palabras praeclari ( $\mathrm{F} \mathrm{f.17r,} \mathrm{1.9),} \mathrm{cla-}$ rissime $\left(\mathrm{F} \mathrm{f.17v,} \mathrm{1.8)} \mathrm{y} \mathrm{clam} \mathrm{(F} \mathrm{f.21r,} \mathrm{1.22)}{ }^{116}\right.$ presentan con nitidez las dos consonantes $(c$ y $l$ ), cosa que no ocurre en daui. Daui es, sin duda, un error común.

2.3.2. Para concluir, me limitaré a exponer algunas observaciones sobre el aparato crítico (de variantes significativas) ${ }^{117}$ de la edición de Martinelli Tempesta.

En mi opinión, sería conveniente señalar que al final del texto $\mathrm{F}$ presenta explicit (Platonis... feliciter) y que en M se lee Finis. En cuanto a 33 [203a], MT (p.156) ofrece la siguiente información: ipsa $\mathrm{F}$ : ipsa in $\mathrm{M}$. En realidad, en $\mathrm{M}$ se lee ipsa m; pero la $m$ corresponde a la inicial de la palabra moenia, que se escribe íntegra en la línea siguiente ( $\mathrm{M} \mathrm{f.95v,} \mathrm{1.17-18).} \mathrm{Se} \mathrm{trata} \mathrm{de} \mathrm{un} \mathrm{procedimiento} \mathrm{habitual} \mathrm{en} \mathrm{el} \mathrm{manuscrito}$ $\mathrm{M}^{118}$, y así lo indica también a propósito de otros ejemplos MT (p.151). Sin embargo, en este lugar, al parecer, no lo ha advertido. No se trata, pues, de una variante del aparato crítico. Por último, en 156 [209c] MT (p.160) señala como variante: $o$ F: quam M. Sin embargo, en ambos manuscritos ${ }^{119}$ se lee: esto, inquam, o optime.

\section{CONCLUSIONES}

Las conclusiones del presente trabajo están repartidas a lo largo de estas páginas. Se basan en el análisis atento del texto del Lysis de Decembrio, para el que he revisado con precisión los manuscritos que lo transmiten ( $\mathrm{F}$ y M), el manuscrito del texto griego que manejó Decembrio (Wroc), las dos ediciones existentes de la traducción de este diálogo (Gallego Moya 2001 y Martinelli Tempesta 2009), y el artículo de Martinelli Tempesta en 2010.

A partir de estos datos, he tratado de explicar las diferencias que existen entre el texto de una y otra edición, corrigiendo y ampliando la información cuando ha sido necesario, y presentando nuevas propuestas. Se ofrecen también algunas observaciones sobre el aparato crítico.

Las diferencias fundamentales entre las dos ediciones se deben a que Gallego Moya escoge $\mathrm{F}$ como manuscrito base (por considerarlo, como se reconoce, más cercano al original del autor), y Martinelli Tempesta escoge M (conjeturando que algunos cambios que presenta $\mathrm{M}$ respecto a $\mathrm{F}$-destinados sobre todo a acercar la traducción lati-

\footnotetext{
116 En clam, $c$ y $l$ están ligeramente más juntas que en praeclari y clarissime; probablemente se deba a que clam es la última palabra de la línea (1.22).

117 Sin detenerme en los apéndices A y B.

118 Ocurre en otros lugares de M: por ejemplo, en f.95r, 1.3-4, donde se lee $n$ al final de la línea 3 y $n e$ al principio de la 1.4; o en f.9r, 1.5-6, donde se lee $p$ al final de la 1.5 y postulare a comienzos de 1.6.

${ }^{119}$ Cf. M f.98v, 1.2-3 y F f.20r, 1.17-18.
} 
na al texto griego- son debidos al propio Decembrio, por lo que M sería la versión última del Lysis).

Una vez más, la revisión del texto me lleva a concluir que $\mathrm{F}$ debe ser considerado el manuscrito base, porque, además de estar más cerca del original del autor, presenta generalmente lecturas más correctas que $\mathrm{M}$, sobre todo en lugares significativos. El modelo de F parece mejor (por ejemplo, presenta incipit y explicit, ausencia que sorprende en M) y el copista entiende mejor el texto.

En cuanto a M, no podemos estar seguros de que los cambios que presenta respecto a $\mathrm{F}$ sean debidos al propio Decembrio. En realidad, los cambios son muy pocos; solo algunos tratan de acercar la traducción latina al texto griego (es el caso, por ejemplo, de perpulchri y pulcher -frente a perdocti y doctus de F- como traducción de

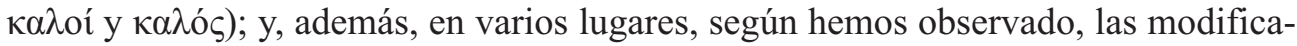
ciones no suponen mejoras del texto de $\mathrm{F}$ (por ejemplo, posita est de $\mathrm{M}$ frente a sita est de $\mathrm{F}$, maxime de $\mathrm{M}$ frente a facile de $\mathrm{F}$, o felicitas est (...) de $\mathrm{M}$ frente a felices (...) de F). Por último, llama la atención que en esta revisión queden sin modificar palabras como, por ejemplo, melior, puellas o illa que se mantienen en $\mathrm{M}$ como traducción de $\kappa \alpha \lambda \lambda i ́ \omega v, \tau \grave{\alpha} \pi \alpha 1 \delta ı \kappa \alpha ́$, o ó $\delta \dot{\varepsilon}$, respectivamente.

Así pues, considero que la propuesta de tomar $\mathrm{F}$ como manuscrito base de la edición del Lysis es más prudente, sobre todo mientras no se sepa con seguridad quién realizó los cambios que presenta $\mathrm{M}$.

En cuanto a la filiación de los manuscritos, me parece muy coherente seguir proponiendo la existencia de un arquetipo del que procederían, a través de copias intermedias, los manuscritos F y M. Así lo confirman errores comunes como daui o moribus, como he explicado supra, e igualmente otras faltas, aparentemente banales, que ya corregí en mi edición de $2001^{120}$.

Como decía al comienzo, la traducción latina debida a Pier Candido Decembrio del Lysis de Platón ha tenido, después de tantos siglos, la atención que merecía; y, sin duda, seguirá siendo objeto de estudio. Las aportaciones de ambas ediciones, del artículo de Martinelli Tempesta en 2010 y del presente trabajo han contribuido, en mi opinión, a mejorar la comprensión del texto de Decembrio. Con toda seguridad, aguardan estudios y ediciones que, con nuevos descubrimientos, seguirán en esa línea de mejora.

\section{REFERENCIAS BIBLIOGRÁFICAS}

CAPpelli, A. (1985), Dizionario di abbreviature latine ed italiane, Milán, Editore Ulrico Hoepli Milano.

Castro De Castro, D. - Gallego moya, E. (2010): «Texto y contexto en la traducción humanista: la versión del Lisis de Platón por Pier Candido Decembrio», en Aullón DE Haro, P. (ed.), Teoría del humanismo, V, Madrid, Verbum, pp.9-33.

Ernout, A. - Thomas, F. (1964, 1951²), Sintaxe latine, París, Éditions Klincksieck.

120 Véase supra, nota 30. 
Fera, V. (2005), «Filologia in casa Decembrio», en Vegetti, M. - Pissavino, C. (a cura di), I Decembrio e la tradizione della Repubblica di Platone tra Medioevo e Rinascimento, Nápoles, pp.144-175.

Ficinus, M. (1546). Cf. [Platón] Omnia diui Platonis Opera.

Gallego Moya, E. (2001), «La versión latina de Pier Candido Decembrio del Lysis de Platón», en Körkel, B.- Licht, T. - Wiendlocha, E., Mentis amore ligati. Lateinische Freundschaftsdichtung und Dichterfreundschaft in Mittelalter und Neuzeit. Festgabe für Reinhard Düchting zum 65. Geburstag, Heidelberg, Mattes Verlag, pp.93-114.

González Rolán, T. - Moreno Hernández, A. - SAquero SuÁrez-Somonte, P. (2000), Humanismo y teoría de la traducción en España e Italia en la primera mitad del siglo XV, Madrid, Ediciones Clásicas.

Hankins, J. (1990), Plato in the Italian Renaissance, I-II, Leiden - London.

KÜHNER, R. - StEGMANN, G. (1992, 1914¹), Ausführliche Grammatik der lateinischen Sprache, Hannover, Verlag Hahnsche Buchhandlung.

LÖFstedt, E. (1962), Philologischer Kommentar zur Peregrinatio Aetheriae. Untersuchungen zur Geschichte der lateinischen Sprache, Uppsala: Universitäts Arsskrift.

Martinelli Tempesta, S. (1995), «Un nuovo codice di Bartolomeo da Montepulciano: Wroc. Ms. Akc. 1949/60», Acme 48. 17-45.

Martinelli Tempesta, S. (1997), La tradizione testuale del Liside di Platone, Pubblicazioni della Facoltà di Lettere e Filosofia dell’Università degli Studi di Milano 173. Sezione di Filologia Classica 6, Florencia, La Nuova Italia.

Martinelli Tempesta, S. (2009), Platonis Euthyphron Francisco Philelfo interprete. Lysis Petro Candido Decembrio interprete, Florencia, Sismel. Edizioni del Galluzzo.

Martinelli Tempesta, S. (2010), «Ancora sulla versione del "Liside" platonico di Pier Candido Decembrio», Acme 63.2. 263-270.

[Platón] Omnia diuini Platonis Opera tralatione Marsilii Ficini, emendatione et ad graecum codicem collatione Simonis Grynaei, summa diligentia repurgata, quibus subiectus est, Index quam copiosissimus, Basileae, in officina Frobeniana, 1546.

[Platón] Platonis augustiss. philosophi omnium quae extant operum, Tomus secundus graece et latine ex nova Ioannis Serrani interpretatione, perpetuis eiusdem notis illustrata (...), [Parisiis 1578]. (En el t. I (la obra consta de tres tomos) se lee: Excudebat Henr. Stephanus, 1578).

Rodríguez Adrados, F. (1956), Líricos griegos. Elegíacos y yambógrafos arcaicos (siglos VII-V a.C.), I, Barcelona, Alma Mater.

Serranus, Io. (1577). $C f$. [Platón]. Platonis augustiss. Philosophi.

VÄÄNÄNEN, V. (1987), Le Journal-épître d'Égérie (Itinerarium Egeriae). Étude linguistique, Helsinki, Suomalainen Tiedeakatemia.

ZaCCARIA, V. (1956), «Sulle opere di Pier Candido Decembrio», Rinascimento 7, 13-74. 